\title{
Planning for Community Relocations Due to Climate Change in Fiji
}

\author{
Karen E. McNamara ${ }^{1} \cdot$ Helene Jacot Des Combes ${ }^{2}$
}

Published online: 21 September 2015

(C) The Author(s) 2015. This article is published with open access at Springerlink.com

\begin{abstract}
As a consequence of the impacts of climate change, some households and entire communities across the Pacific are making the complex and challenging decision to leave their homelands and relocate to new environments that can sustain their livelihoods. This short article charts how the residents of Vunidogoloa village in Fiji relocated in early 2014 to reduce their vulnerability to encroaching sea level and inundation events that regularly devastated the community. As a consequence of the Vunidogoloa relocation, this article also explores how the Fiji Government is planning for similar resettlement transitions, including vulnerability and adaptation assessments to develop a list of potential community relocations and the development of national relocation guidelines. This study draws from key informant interviews $(n=8)$ with government officials, as well as representatives from intergovernmental and local nongovernmental organizations, who are involved in the relocation issue. Given the speed at which these national, top-down initiatives are being forged and especially in light of the absence of any mention of relocation in Fiji's 2012 climate change policy, careful and inclusive engagement across all scales and stakeholders, including communities "earmarked" for relocation, is paramount.
\end{abstract}

Karen E. McNamara

karen.mcnamara@uq.edu.au

1 School of Geography, Planning and Environmental Management, The University of Queensland, Brisbane 4072, Australia

2 Pacific Centre for Environment and Sustainable Development, University of the South Pacific, Suva, Fiji
Keywords Climate change - Community relocation · Fiji $\cdot$ Risk planning $\cdot$ Sea level rise

\section{Introduction}

Numerous studies have illustrated the serious risks posed by climate change for the short- and long-term sustainability of island communities throughout the Pacific region, particularly in relation to food and water security, health, industry, and community infrastructure (Barnett and Adger 2003; Mimura et al. 2007; Barnett and Campbell 2010). According to Nurse et al. (2014), small islands are especially vulnerable to sea level rise, cyclones, increasing air and sea surface temperatures, and changing rainfall patterns. More specifically, increased sea level in conjunction with extreme sea level events, such as waves and storm surges, will reduce arable land, affect groundwater reserves, and increase the risk of flooding and erosion in coastal areas as well as infrastructure damage (Nurse et al. 2014). Yet, these changes and impacts are not experienced equally throughout the region, in part due to varying island types (particularly low vs. high islands). Low islands are most vulnerable as only a modest sea level rise could cover most of their territorial space. The coastal areas of high islands are also vulnerable but sea level rise does not threaten the very existence of the nation. This is the case for Fiji, which is comprised of both low and high islands, but with the majority of its population concentrated on the two largest islands. Notwithstanding, Fiji will be significantly affected by changes in the climate system, with severe consequences projected for local economies and people's livelihoods.

While current adaptation programs seek to reduce the exposure of communities and increase their adaptive 
capacity, these adaptation measures only cater for a certain range of climate change impacts. The worst case scenario will see communities having to migrate or relocate as their only long-term strategy. In this vein, an increasing number of studies point to how the impacts of climate change now influence, and will continue to influence, where people live throughout the world (Hugo 1996; Warner et al. 2009). For some researchers, migration is pitched as an adaptation response to the impacts of climate change (Black et al. 2011), while for others it is portrayed as a negative impact of climate change and a failure of in situ adaptation efforts (Felli and Castree 2012). Framing migration as an adaptation solution in a straightforward manner can provide little opportunity for people to "lead the kind of lives they value in the places where they belong" (Adger and Barnett 2005, p. 328). In a study of residents in Funafuti, the capital of Tuvalu, it was found that people wished to remain living in their ancestral homelands, citing "reasons of lifestyle, culture and identity" (Mortreux and Barnett 2009, p. 105). Sense of place, linked to identity and agency, along with rights to land and culture, should not be overlooked in these discussions.

A major gap in our understanding of climate change and mobility relates to the relocation of entire communities (with exceptions including Bronen 2011). Other studies, particularly related to development-induced relocations and resettlements, highlight some key challenges of relocating entire communities (Asthana 1996; Cernea 1997; Scudder 2012). The overwhelming sense is that relocations are "rarely considered successful by those who move" (McAdam 2015, p. 32). We must take heed of this and learn from past mistakes.

This exploratory study describes the processes by which an entire community in Fiji has recently relocated as a consequence of frequent flooding, inundation, and failed seawalls. We utilize the term relocation throughout to describe this process of moving infrastructure and homes to a new destination, which has been the term used locally in Fiji.

\section{Aim and Method}

Having just held the Chair of the Group of 77 (plus China) at the international climate change talks and also having released its National Climate Change Policy (NCCP) in 2012, which matched the establishment of a new Climate Change Division, the Fiji Government is taking significant strides to address climate change. Relocation as a consequence of the impacts of climate change is also high on the government's agenda despite it not being mentioned at all in the NCCP. In recent years, not only have communities approached the Fiji Government for assistance to relocate, the government also is undertaking extensive vulnerability and adaptation assessments across the country to ascertain high risk and priority sites for potential relocation, and is developing national relocation guidelines.

This is all moving quickly. This article examines how the government is planning for community relocations as a growing consequence of the impacts of climate change. This study also explores the key "initial phase" processes for the recent relocation of Vunidogoloa village and the role of the government in this endeavour. Figure 1 shows the location of Fiji and Vunidogoloa village in relation to the Pacific Islands region.

Interviews were undertaken as a means of gathering qualitative data on this issue (Dunn 2005). A number of indepth interviews were undertaken with government officials including key ministers and officials $(n=2)$, relevant intergovernmental organizations $(n=3)$ and nongovernmental organizations $(n=3)$ in October 2014. Undertaken in English, these exploratory interviews garnered information about how the Fiji Government is planning for relocation challenges across the country in the near future, and elicited details of the recent Vunidogoloa village relocation.

\section{Preliminary Lessons from Vunidogoloa Village, Fiji}

These preliminary lessons have been derived from the views of outside stakeholders involved in facilitating the relocation, not the affected community themselves, which very much warrants further investigation. The original Vunidogoloa village consisted of 26 houses and was located only a few meters from the coast on Vanua Levu in the northern part of the country. Over time, the community became consistently inundated and trapped when heavy rains combined with high tides (Pacific Conference of Churches 2012). Despite the houses being built on stilts, flood waters still reached the ground floors and caused damage each time the village was inundated. Growing and sustaining local community gardens also became increasingly difficult to maintain due to the saltwater intrusions. In an initial attempt to mitigate the saltwater intrusions and protect the community, a seawall was constructed, however, over time this barrier became ineffective.

In 2007, the community approached the Fiji Government (first through the local government offices) for financial assistance to relocate elsewhere. In January 2014, the village finally relocated to a new site within the customary land boundaries of the community. Thirty new homes were built $2 \mathrm{~km}$ from the original village site. The community made the decision on where to relocate and designed their new village, which included their desire for neighbors to remain the same. 

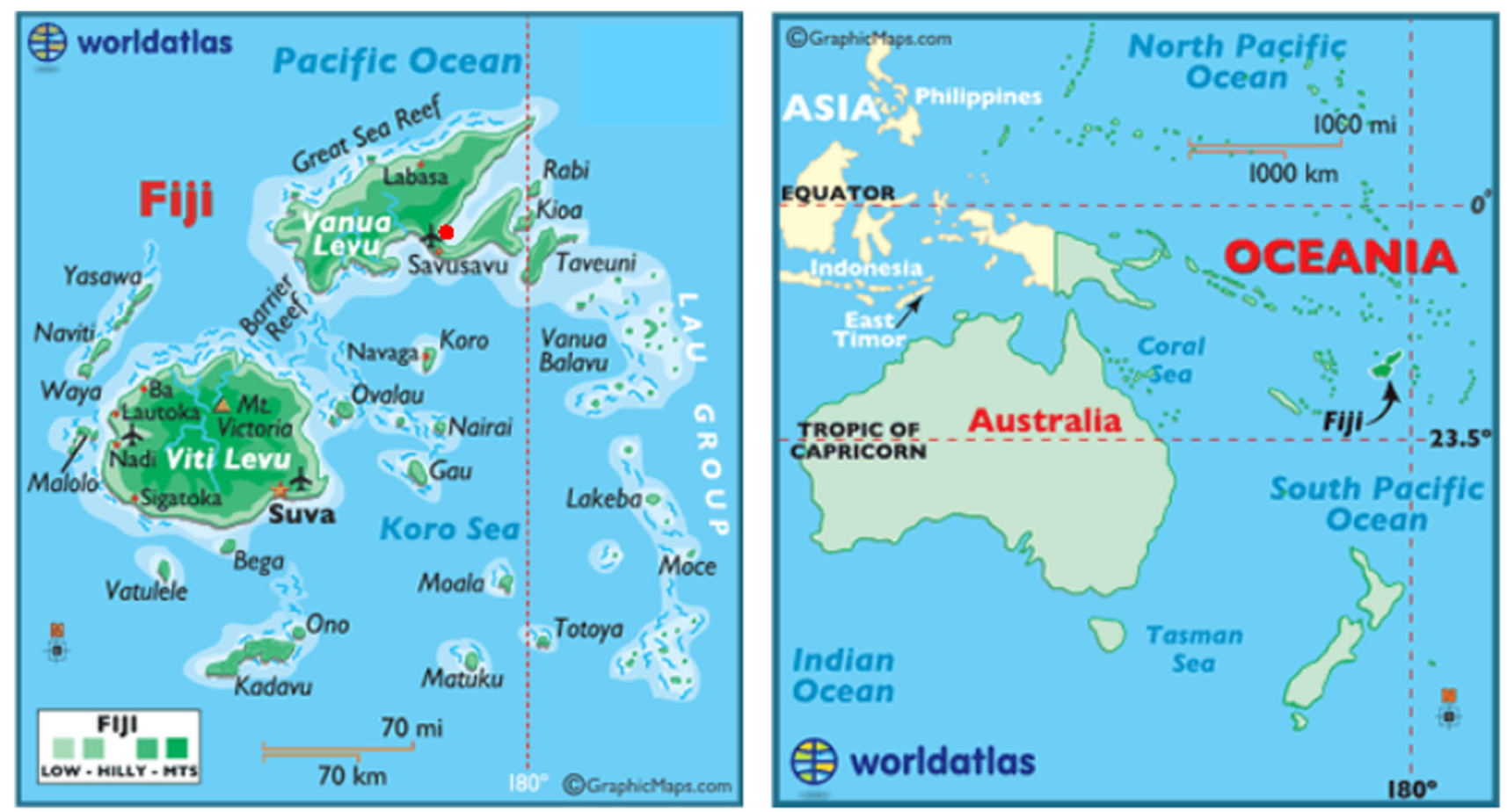

Fig. 1 The location of Fiji and Vunidogoloa village (red circle) in relation to the Pacific Islands region. Source http://www.worldatlas.com

Relocation is costly-financially, psychologically, and socially. For these reasons, among others, it is often the option of last resort for communities (McNamara and Gibson 2009). For the Fiji Red Cross, this concern was noted in an interview: "It takes time, it takes effort, and it is a very costly activity to do, that is why we have a lot of disaster risk reduction and climate change adaptation activities that are being implemented in Fiji communities" (Fiji Red Cross interviewee, personal communication, 29 October 2014, Suva, Fiji). As an option of last resort, this position was made clear in an interview with a climate change policy officer, speaking on behalf of the Climate Change Division of the Fiji Government: "When it comes to relocation it's the last resort for us; we want to be able to do it in a way that is very, very holistic; it's not about moving houses, it's about moving lives" (Government Climate Change Division interviewee, personal communication, 30 October 2014, Suva, Fiji).

For Vunidogoloa village, relocation was their option of last resort as a means of sustaining livelihoods in the longterm. As part of the relocation, the earthworks alone cost the Fiji Government around FJ $\$ 500,000$, which converts to approximately USD 230,000 (Pacific Conference of Churches interviewee, personal communication, 29 October 2014, Suva, Fiji). There were also a number of activities that accompanied the relocation process to ensure the effectiveness of this "initial phase." The first activity related to the role of the local community in the relocation itself. They provided timber from their customary lands to be used for construction, mainly housing, at the new site to help defray costs (Government Climate Change Division interviewee, personal communication, 30 October 2014, Suva, Fiji). The provision of resources and human capital were essential in contributing to the relocation, and ensuring that community members were very much part of the relocation efforts.

The second activity ensuring the durability of this "initial phase" relocation effort related to the support provided from external organizations to help initiate new industries at the relocated site. For example, the Department of Fisheries provided fish ponds as the community could no longer easily access the ocean for their own subsistence needs and to sell ocean fish produce. This shift to fish ponds is a major livelihood change and one that should be investigated further to identify the effectiveness of such a transition. Also, the International Labour Organization (ILO) offered support, as explained in an interview with a program officer: "The government played a major part; our assistance to them was we provided pineapple tops, banana shoots, as well as the construction of the copra dryer as in-kind support to the crop rehabilitation and livelihood program" (ILO interviewee, personal communication, 30 October 2014, Suva, Fiji). The local community was then tasked with planting the banana and pineapple, which again assisted in transferring ownership to them in terms of developing new livelihood strategies. Again, these shifts in livelihood strategies should be monitored over time to understand their ongoing function and utility in the community. 
The third and final activity related to the community's ability to relocate to land within their customary territory. The community was fortunate to have higher ground to move to within their land boundaries, making it an easier transition. According to the interviewees, this was a key reason for why the relocation, to date, has been considered successful - the village relocated to land owned by the same community and no one in the community contested the use of the new site on which to relocate the village. Because suitable resettlement sites will not always be possible in every relocation case, protocols and mechanisms must be established to facilitate the discussions between the communities that wish to relocate and customary land owners, which might involve some form of compensation.

\section{Planning Relocations: Fiji Government's Responses}

With a growing concern that more communities throughout Fiji will seek to relocate in both the short- and long-term, the Fiji Government is currently undertaking nation-wide community-based vulnerability and adaptation assessments. These assessments, which are still ongoing, will result in a list of potential sites in need of relocation. When probed about whether approximately 42 potential communities might need relocation, which was the speculative number provided to the authors from the Pacific Conference of Churches, a government representative responded: "We are in a moment of stocktaking so to speak. As far as the climate change division is concerned, I don't believe that we have an official number, but, that number [42] does not sound off the mark" (Government Climate Change Division interviewee, personal communication, 30 October 2014, Suva, Fiji). If there is truth to this figure, a large number of communities have been "earmarked" for relocation across Fiji.

In conjunction with these assessments, national relocation guidelines are being drafted. But there can be a potential downside to this. In Fiji this relocation list and guidelines are being forged in haste but still await finalization. The need for pragmatism was echoed in an interview with a UNHABITAT programme manager: "relocation, planned or otherwise, is an option of last resort, and great care needs to be taken to ensure that the identified climate change threats are indeed the key cause of the need to relocate" (UNHABITAT interviewee, personal communication, 29 October 2014, Suva, Fiji). The concern here is that these guidelines may be pushed by other agendas: "Climate change has, by some, been hijacked for opportunist and political purposes and can undermine the genuine efforts of those attempting to adapt to very real environmental threats"
(UN-HABITAT interviewee, personal communication, 29 October 2014, Suva, Fiji). The relocation guidelines, which do not appear to be done in consultation with any potentially affected communities, should not be hurried, and they also require sensitive and participatory planning. Time will tell how well these guidelines consider issues of rights to land, culture, and local sovereignty, and ensure that the needs and aspirations of communities and people are placed center stage.

\section{Conclusion}

The relocation of Vunidogoloa village has highlighted the complexity of the process. It has also shed light on some key ingredients that have proven to be very useful in the "initial phase" of community relocations. Some of these ingredients are more straightforward, such as the need for communities to lead the relocation decision-making process (in terms of when, how, where) and also provide resources and human capital (where possible). Inter-agency technical and financial cooperation is also needed to assist with the relocation and help ensure sustainable livelihood options (in the short- and long-term). Less straightforward are issues related to the availability of land to relocate to, especially if communities cannot relocate within their customary land boundaries.

But the question remains: will the hasty movement of the government to develop a relocation list and guidelines result in the type of relocation failures that are commonplace elsewhere? Or is the government showing leadership through forward planning? As we wait and see, we can only hope that this process is guided by a multiscalar consultation process that involves the extensive participation from communities that are earmarked for this arduous process.

Open Access This article is distributed under the terms of the Creative Commons Attribution 4.0 International License (http://crea tivecommons.org/licenses/by/4.0/), which permits unrestricted use, distribution, and reproduction in any medium, provided you give appropriate credit to the original author(s) and the source, provide a link to the Creative Commons license, and indicate if changes were made.

\section{References}

Adger, N., and J. Barnett. 2005. Compensation for climate change must meet needs (Correspondence). Nature 436(7049): 328.

Asthana, R. 1996. Involuntary resettlement: Survey of international experience. Economic and Political Weekly 31(24): 1468-1475.

Barnett, J., and N. Adger. 2003. Climate dangers and atoll countries. Climatic Change 61(3): 321-337.

Barnett, J., and J. Campbell. 2010. Climate change and small island states: Power, knowledge and the South Pacific. London: Earthscan. 
Black, R., S.R.G. Bennett, S.M. Thomas, and J.R. Beddington. 2011. Climate change: Migration as adaptation. Nature 478(7370): 447-449.

Bronen, R. 2011. Climate-induced community relocations: Creating an adaptive governance framework based in human rights doctrine. N.Y.U. Review of Law and Social Change 35(2): $101-148$

Cernea, M. 1997. The risks and reconstruction model for resettling displaced populations. World Development 25(10): 1569-1587.

Dunn, K.M. 2005. Interviewing. In Qualitative research methods in human geography, 2nd edn, ed. I. Hay, 79-105. Melbourne: Oxford University Press.

Felli, R., and N. Castree. 2012. Neoliberalising adaptation to environmental change: Foresight or foreclosure? Environment and Planning A 44(1): 1-4.

Hugo, G. 1996. Environmental concerns and international migration. International Migration Review 30(1): 105-131.

McAdam, J. 2015. Lessons from planned relocation and resettlement in the past. Forced Migration Review 49: 30-32.

McNamara, K.E., and C. Gibson. 2009. "We do not want to leave our land": Pacific ambassadors at the United Nations resist the category of climate refugees. Geoforum 40(3): 475-483.

Mortreux, C., and J. Barnett. 2009. Climate change, migration and adaptation in Funafuti, Tuvalu. Global Environmental Change 19: $105-112$.
Mimura, N., L. Nurse, R.F. McLean, J. Agard, L. Briguglio, P. Lefale, R. Payet, and G. Sem. 2007. Small Islands. In Contribution of Working Group II to the fourth assessment report of the Intergovernmental Panel on Climate Change, 2007, ed. M.L. Parry, O.F. Canziani, J.P. Palutikof, P.J. van der Linden, and C.E. Hanson, 687-716. Cambridge: Cambridge University Press.

Nurse, L.A., R.F. McLean, J. Agard, L.P. Briguglio, V. DuvatMagnan, N. Pelesikoti, E. Tompkins, and A. Webb. 2014. Small Islands. In Contribution of Working Group II to the fifth assessment report of the Intergovernmental Panel on Climate Change, ed. V.R. Barros, C.B. Field, D.J. Dokken, M.D. Mastrandrea, K.J. Mach, T.E. Bilir, M. Chatterjee, K.L. Ebi, et al., 1613-1654. Cambridge: Cambridge University Press.

Pacific Conference of Churches. 2012. The 'Bula Bulletin' (AprilMay 2012). Suva: Pacific Conference of Churches.

Scudder, T.T. 2012. The future of large dams: 'Dealing with social, environmental, institutional and political costs'. London: Earthscan.

Warner, K., C. Ehrhart, A. Sherbinin, S. de Adamo, and T. Chai-Onn. 2009. In search of shelter: Mapping the effects of climate change on human migration and displacement. A policy paper prepared for the 2009 Climate Negotiations. Bonn: United Nations University, CARE and CIESIN-Columbia University. 